\title{
Proton Exchange Membrane Fuel Cell Flooding Caused by Residual Functional Groups after Platinum Atomic Layer Deposition
}

Alia M. Lubers ${ }^{1}$, William W. McNeary ${ }^{1}$, Daryl J. Ludlow ${ }^{2}$, Austin W. Drake ${ }^{1}$, Matthias Faust ${ }^{3}$, Megan E. Maguire $^{1}$, Maila U. Kodas ${ }^{1}$, Martin Seipenbusch ${ }^{3}$, Alan W. Weimer ${ }^{1 *}$

${ }^{1}$ Department of Chemical and Biological Engineering, University of Colorado Boulder, Boulder, Colorado, USA

${ }^{2}$ Ludlow Electrochemical Hardware, Rensselaer, New York, USA

${ }^{3}$ Nanopartikeltechnologie Gruppe, Karlsruher Institut für Technologie, Karlsruhe, Baden-Württemberg, Germany

*Corresponding author email: alan.weimer@colorado.edu; phone: (303) 492-3759

\begin{abstract}
Proton exchange membrane fuel cell (PEMFC) catalysts manufactured using atomic layer deposition (ALD) on unmodified and functionalized carbon were compared to a commercial catalyst in half- and whole-cell tests. Half-cell tests showed the ALD catalyst performed better or comparable to a commercial catalyst. Conversely, whole-cell tests revealed flooding in the ALD catalyst produced on functionalized carbon. Residual functional groups had reduced the hydrophobicity, and rendered this catalyst impractical for use in whole-cell PEMFC applications. However, the ALD catalyst produced on unmodified carbon performed better than the commercial catalyst, which illustrates the power of ALD on appropriate catalyst supports.
\end{abstract}




\title{
Keywords
}

platinum fuel cell catalyst; functional groups; half-cell; whole-cell; hydrophobicity; water management

\begin{abstract}
Abbreviations
Atomic layer deposition (ALD); platinum on carbon (Pt/C); proton exchange membrane fuel cell (PEMFC); diffuse reflectance infrared Fourier transform spectroscopy (DRIFTS); trimethyl(methylcyclopentadienyl)platinum(IV) (MeCpPtMe3); oxygen reduction reaction (ORR); electrochemical surface area (ECSA)
\end{abstract}

\subsection{Introduction}

Invented at the infancy of electricity generation during the 1830s [1], fuel cells have enabled efficient and direct chemical to electrical energy conversion [2]. Recently, stationary [3], space [4] and automotive [5] industries have adopted fuel cells for practical and sustainable electricity generation. Costcompetitive market demand requires further optimization of fuel cell systems and their manufacturing [6]. Here, atomic layer deposition (ALD) for fuel cell catalyst fabrication was explored in both half-cell and whole-cell systems.

In brief, ALD was used to grow platinum nanoparticles on a commercial carbon support, XC72R. One ALD half-cycle consisted of a vapor organometallic precursor deposition on the XC72R surface. To complete the cycle, the ligands were removed with a hydrogen dose. Since reactions are surface limited, a sub-monolayer of platinum is grown with each ALD cycle, which coalesce into nanoparticles [7]. A myriad of precursors can deposit ceramics or metals, depending on the chemistry [8]. Repeated ALD cycles deposit a film or nanoparticles concisely on a support. ALD has been used to generate many types of catalysts $[9,10]$. High throughput ALD on particle substrates is easily achieved in a fluidized bed reactor $[7,11-14]$ and is adaptable for industrial-scale catalyst manufacture. Often, functional groups are placed on the substrate to facilitate deposition [15-17]. A previous study developed ALD as a large-scale method to produce PEMFC catalysts via combustion or hydrogenation chemistries, on plain or 
functionalized carbon [18]. In this report, catalysts grown from a hydrogen ALD chemistry were evaluated for promoting the oxygen reduction reaction (ORR). The ALD-derived catalyst on XC72R without functional groups was found to have better performance than a commercial catalyst, advocating ALD as an effective synthesis methodology for PEMFC catalysts. However, the performance results on a functionalized substrate were influenced by type of cell, and the conditions therein.

The bulk of literature presents half-cell evaluation for promising PEMFC catalysts within a liquid electrolyte environment. Naturally, the components of whole-cell tests convolute performance relative to half-cell measurements due to two electrodes and a multitude of interfaces. Additionally, both triple- and two-phase boundaries dominate function within the cell [19]. Despite complex processes, based on our results we recommend only a whole-cell configuration can reveal ultimate catalyst performance for electrical generation. Furthermore, the effect of altering interfaces can be exploited more effectively within a whole-cell, such as varying Nafion ${ }^{\circledR}$ or Teflon ${ }^{\circledR}$ content in a catalyst layer [20-22]. We found comparison of half- and whole-cell tests can leverage interfacial effects in either environment to provide a more thorough investigation of PEMFCs materials. By also varying water management methodology within the whole-cell, residual hydrophilic surface groups prone to flooding on a functionalized catalyst were determined to contribute to diminished cell performance. This is the first study to compare plain and functionalized carbon support materials for ALD-prepared catalysts in both half-cell and whole-cell PEMFC configurations.

\subsection{Experimental methods}

\subsection{ALD catalyst synthesis and material characterization}

Platinum nanoparticles were deposited on unmodified or functionalized XC72R carbon support materials by ALD according to a previous report [18]. To summarize, XC72R was functionalized by refluxing in nitric acid for $9 \mathrm{hr}$. During ALD, trimethyl(methylcyclopentadienyl)platinum(IV) vapor was dosed by flowing $5 \mathrm{sccm}$ of nitrogen through a bubbler of platinum metalorganic at $40{ }^{\circ} \mathrm{C}$. This vapor 
flowed through a fluidized bed containing 2 grams of unmodified (plain) or functionalized XC72R. In a subsequent dose, $20 \%$ hydrogen balance argon at $5 \mathrm{sccm}$ was used for ligand removal. Pure nitrogen at 5 sccm was used as a purge gas between precursor doses. All depositions occurred at $300{ }^{\circ} \mathrm{C}$ and an in-line high-pressure gas analyzer series QMS200 mass spectrometer (Stanford Research Systems) monitored breakthrough, where breakthrough was indicative of reaction completion for each precursor dose. One ALD cycle consisted of a 40 min platinum precursor dose, a 70 min nitrogen purge, a 90 min second precursor dose (20\% hydrogen balance argon), and a 180 min nitrogen purge. Each ALD catalyst was generated from 5 total cycles. ALD catalysts were compared to a commercial catalyst, Premetek P10A200 with nominal 20wt\% platinum on XC72R.

Reported previously, TEM imaging was produced from a CM-100 microscope (Phillips). Platinum weight loading of the $\mathrm{Pt} / \mathrm{C}$ catalysts was measured by inductively coupled plasma optical emission spectroscopy (ICP-OES) after digestion in an HF/aqua regia solution for $24 \mathrm{hr}$. Platinum particle size, dispersion, and surface area were determined using $\mathrm{H}_{2}$ chemisorption by an AS-1 Autosorb (Quantachrome). The XC72R surface before and after platinum deposition was inspected by diffuse reflectance infrared Fourier transform spectroscopy (DRIFTS) using a Nicolet 6700 FT-IR (Thermo Scientific) with a closed cell attachment.

A LECO combustion oxygen analyzer (LECO Corp TC600) determined total oxygen content. Analysis was calibrated using a 20\% tungsten trioxide standard (oxygen 502-141, green powder).

\subsection{Electrochemical half-cell evaluation}

Catalysts were evaluated for ORR efficacy using a rotating disk electrode (RDE). Catalysts inks were synthesized from $1.5 \mathrm{mg}$ of $\mathrm{Pt} / \mathrm{C}, 7.5 \mathrm{~mL}$ of ink solution containing $76 \%$ (v/v) deionized water with balance isopropyl alcohol, and $30 \mu \mathrm{L}$ of $\mathrm{Nafion}{ }^{\circledR}$ dispersion (LQ-1105 - $1100 \mathrm{EW}$ at $5 \%$ weight). The mixture was sonicated for $20 \mathrm{~min}$ or until homogenous. The ink was drop-coated onto a $0.196 \mathrm{~cm}^{2}$ glassy carbon electrode (Pine Research Instrumentation) in two $10 \mu \mathrm{L}$ casts. The electrode was rotated in an 
inverted configuration at $700 \mathrm{rpm}$ to ensure uniform dispersion of catalyst [23] by a rotator (Pine Research Instrumentation).

The $\mathrm{Pt} / \mathrm{C}$ catalyst dispersions were evaluated as the working electrode in a $0.1 \mathrm{M} \mathrm{HClO}_{4}$ electrolyte, with a Pt coil as the counter electrode, and a saturated calomel electrode (SCE, Gamry) as the reference electrode. Initially, the cell electrolyte was purged with pure nitrogen for 20 min followed by conditioning of the stationary working electrode by 100 cyclic voltammograms (CVs) between $0.00 \mathrm{~V}$ vs SCE and $1.20 \mathrm{~V}$ vs SCE at $500 \mathrm{mV} / \mathrm{s}$ by a Reference 3000 Potentiostat (Gamry). Electrochemical surface area (ECSA) of the platinum catalyst was determined by the third cycle of three CVs at $0.05 \mathrm{~V}$ vs SCE to $1.20 \mathrm{~V}$ vs SCE at $50 \mathrm{mV} / \mathrm{s}$, assuming hydrogen adsorption of $210 \mu \mathrm{C} / \mathrm{cm}^{2}$ of Pt [23]. Background scans were performed by CV between $1.03 \mathrm{~V}$ vs SCE to $0.05 \mathrm{~V}$ vs SCE at $20 \mathrm{mV} \mathrm{s}^{-1}$, and subtracted from the polarization analysis to account for Pt oxidation/reduction currents. The electrolyte was then purged with pure oxygen for $20 \mathrm{~min}$. At $1600 \mathrm{rpm}$, another CV was performed; the anodic scan provided polarization analysis after background subtraction. Anodic scans were analyzed at $0.2 \mathrm{~V}$ vs SCE (0.503 V vs RHE) for half-wave potential metrics.

\subsection{Electrochemical whole-cell evaluation}

Catalyst inks were fabricated from $3 \% \mathrm{Pt} / \mathrm{C}$ catalyst, $10 \%$ deionized water, $22 \%$ Nafion® dispersion (LQ-1105 - $1100 \mathrm{EW}$ at 5\% weight), and 65\% methanol. The mixture was stirred for $1 \mathrm{hr}$ and sonicated for $3 \mathrm{hr}$. A $25 \mathrm{BC}$ gas diffusion layer (Sigracet) was sprayed with $53 \mu \mathrm{L}$ per $\mathrm{cm}^{2}$ of catalyst ink and left to dry on a glass plate for $24 \mathrm{hr}$, forming the gas diffusion electrode (GDE). Membrane electrode assemblies (MEAs) were fabricated from the catalyst of interest for the cathode, and $20 \%$ platinum on carbon commercial catalyst (Premetek P10A200) containing GDEs for the anode. The proton-conducting layer was prepared by boiling Nafion® 212 (DuPont) in $0.5 \mathrm{M}$ sulfuric acid for $2 \mathrm{hr}$. The hot membranes were rinsed in boiling deionized water 3 times, and left to cool to room temperature in deionized water, where they remained stored. To fabricate MEAs, GDEs were bonded to the wet proton conductor using a heated hydraulic press (Carver Model C) under 500 psi at $130{ }^{\circ} \mathrm{C}$ for $5 \mathrm{~min}$. 
MEA performance was evaluated in a single cell setup (Fuel Cell Technologies) with $10 \mathrm{~cm}^{2}$ active area operated by a fuel cell test stand (Ceres Technologies PEM 221). Featured wet polarization performance was evaluated at $60{ }^{\circ} \mathrm{C}$, with $78 \%$ humidity, with pure hydrogen at 1.2 times the stoichiometric flow on the anode and pure oxygen at 2 times the stoichiometric flow on the cathode after a stabilization hold step at $0.1 \mathrm{~A} / \mathrm{cm}^{2}$ for $6 \mathrm{hr}$. Drier polarization conditions were evaluated at $60{ }^{\circ} \mathrm{C}$, with $61 \%$ humidity, pure hydrogen on the anode at $200 \mathrm{sccm}$ and pure oxygen on the cathode at $200 \mathrm{sccm}$ after purging the cathode with nitrogen for $3 \mathrm{hr}$, and a stabilization step at $0.2 \mathrm{~A} / \mathrm{cm}^{2}$ for $30 \mathrm{~min}$. A potentiostat (Gamry Reference 3000) determined electrochemical impedance spectroscopy at open circuit voltage (OCV) from 100,000 Hz to $0.1 \mathrm{~Hz}$, where ohmic resistance was determined to be the real high frequency intercept on a Nyquist plot. All polarization curves were IR corrected.

\subsection{Surface contact angle measurement}

Wettability of the catalyst layers on the GDEs was evaluated by relative surface contact angle of a water droplet on the surface. Measurements were taken by pipetting a $5 \mu \mathrm{L}$ droplet of $18.2 \mathrm{M} \Omega$-cm ultrapure water onto the planar GDEs in three separate locations on each electrode. The electrodes were then placed on a backlit stage, and images of the droplets were taken using a Dantec Dynamics FlowSense EO camera equipped with a Nikon AF Micro-Nikkor $200 \mathrm{~mm}$ lens. Images of the droplets were analyzed using the Contact Angle plugin in the ImageJ software, in which manual processing of the droplet baseline and surface points allowed for best-fit determination of the drop profile and contact angle.

\subsection{Results \& Discussion}

\subsection{Pt nanoparticle characteristics}


Table 1. Particle characteristics for Pt/C materials synthesized via ALD and a Pt/C commercial catalyst.

\begin{tabular}{|c|c|c|c|}
\hline Catalyst Name & Plain & Functionalized & Commercial \\
\hline \multirow{7}{*}{ 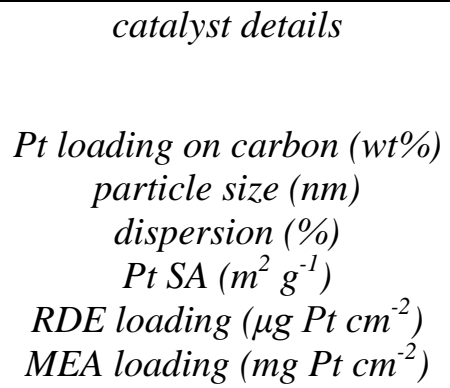 } & $\begin{array}{l}\text { Pt ALD on plain } \\
\text { XC72R }\end{array}$ & $\begin{array}{c}\text { Pt ALD on functionalized } \\
\text { XC72R }\end{array}$ & $\begin{array}{l}20 \mathrm{wt} \% \mathrm{Pt} \text { on XC72R } \\
\text { commercial catalyst } \\
\text { - Premetek P10A200 }\end{array}$ \\
\hline & 21.5 & 22.7 & 19.9 \\
\hline & 3.9 & 2.6 & 3.9 \\
\hline & 29.3 & 43.9 & 29.0 \\
\hline & 15.5 & 24.6 & 14.3 \\
\hline & 4.4 & 4.6 & 4.1 \\
\hline & 0.32 & 0.34 & 0.30 \\
\hline
\end{tabular}

Platinum nanoparticles with differing particle sizes and dispersions (percent of metal on the surface) arose from differences between the carbon substrate, either unmodified (plain) or functionalized XC72R (Table 1) [18]. ALD on plain XC72R produced Pt nanoparticles with equivalent characteristics to the commercial catalyst. ALD on a functionalized XC72R produced smaller and more dispersed Pt particles [18], paralleled by other reports [15, 24-26].

Functional groups remained on the functionalized ALD-catalyst (referred to as functionalized). Previously reported, DRIFTS was used to inspect surface functional groups on plain and functionalized $\mathrm{XC72R}$, and functionalized XC72R after platinum was deposited by ALD [18]. No relevant surface groups were detected on plain XC72R. Anhydride $\left(1780 \mathrm{~cm}^{-1}\right)$, carboxylic acid $\left(1680 \mathrm{~cm}^{-1}\right)$ and quinone $\left(1630 \mathrm{~cm}^{-1}\right)$ oxygen-rich surface groups were found on the functionalized carbon, consistent with covalent functional group formation during nitric acid treatment [27, 28]. After platinum deposition by ALD, some anhydride and quinone groups persisted, albeit partially consumed by the ALD reactions. We assume carboxylic acid groups were completely consumed during the ALD process [18]. Similar conclusions for DRIFTS analysis were drawn from total oxygen analysis (Fig. 1). A slight amount of oxygen was detected on XC72R without functionalization (plain XC72), before platinum deposition, any oxygen detected was assumed to be surface-adsorbed. Oxygen adsorbed on the surface of XC72R even without functionalization was likely necessary for successful metal deposition by ALD on a traditionally difficult 
substrate [18]. When the XC72R was functionalized via nitric acid reflux, oxygen groups were added covalently to the surface resulting in a significant increase in total oxygen content (Fig. 1). It is likely oxygen content was only surface-bound and not from bulk carbon. Half of the oxygen content was consumed during the ALD process. Surface oxygen groups were utilized or covered by Pt deposition, however half of the surface-bound total oxygen content remained. Because the ALD process used a reduction chemistry, the remaining total oxygen content was most likely only on the surface of the carbon owing to the functionalization process, and not produced by the ALD process itself. Consequently, the catalyst on XC72R with functional groups (functionalized) incorporated into the catalyst layer influenced performance during evaluation within a fuel cell, shown in section 3.2 and detailed in section 3.3. However, the ALD-synthesized catalyst on XC72R without functionalization (plain) did not contain functional groups and performed better compared to a commercial catalyst, detailed in section 3.2.

\subsection{Electrochemical performance of ALD-synthesized catalysts}

Initial catalyst evaluations occurred by half-cell tests in a percholoric acid liquid electrolyte, including ECSA (Fig. 2) and ORR activity (Fig. 3). Pt ALD on plain carbon (plain) yielded the highest performance of all catalysts, and Pt ALD on functionalized carbon (functionalized) and the commercial catalyst had similar performance. Normalized by ECSA, surface activity followed higher current generation trends. Next, catalysts were evaluated in a whole-cell, with a solid Nafion® electrolyte (Fig. 4, solid markers). Pt ALD on plain carbon had the highest performance of all catalysts. The Pt ALD on functionalized carbon catalyst flooded at low currents, likely due to impeded water flow and is further examined in section 3.3. Comparisons between the plain and commercial catalyst showed the ALDsynthesized catalyst with better performance in both half- and whole-cell evaluation. Although resulting in similar Pt characteristics, ALD likely grew Pt more uniformly, had more advantageous placement of Pt nanoparticles and by virtue of the process, did not modify the relatively inert surface of XC72R. The plain catalyst had the highest surface activity results from the half-cell characterization, and maintained that activity in the whole-cell. These results show ALD can synthesize competitive PEMFC catalysts. 


\subsection{Test condition and surface group influence on catalyst performance}

Performance as a PEMFC catalyst of $\mathrm{Pt}$ on functionalized carbon (functionalized) varies depending on cell environment. Within a half-cell (Fig. 3), performance was similar compared to a commercial catalyst. Despite the ALD-derived catalyst on functionalized XC72R containing higher Pt surface area, surface activity of the commercial catalyst remained competitive. Likely, the smaller size of the Pt nanoparticles was less active for ORR than the commercial and plain catalysts [29].

Despite favorable and similar performance in a half-cell, the ALD-made Pt catalyst on functionalized XC72R (functionalized) displayed significant flooding in a whole-cell (Fig.4, solid markers). The functional groups on the modified carbon incorporated into the catalyst layer compromised the phase boundaries when interfaced with $N a f i o n \AA$ and platinum. Water management was mitigated by these functional groups still present on the surface. Similarly, Martin et al. measured loss of mass-activity at larger currents for electrodeposited Pt on a functionalized carbon [30]. Performance improved under drier whole-cell conditions with lower relative humidity and a higher gas flowrate through the cell (Fig. 4, hallow markers). Lower humidity and higher gas flowrate enabled better water management for the compromised surface of the functionalized catalyst, whereas performance decreased overall for the commercial catalyst. Perceptible performance for moderate currents on the functionalized catalyst was only detected in this drier environment. Within the drier condition, only at higher currents were the compromising effects of the surface groups sufficient for the commercial catalyst performance to match the functionalized performance. The drier conditions of lower humidity and higher gas flow rate also benefited the commercial catalyst at higher currents compared to its evaluation in wet conditions. However, higher relative humidity is recommended for PEMFC operation at modest current densities [31, 32]. Higher gas flowrate tends to increase cell performance [33], however is impractical for steady state operation. Surface effects were not observed in the half-cell and are attributed to the characteristics of the catalyst layer of the GDE and the solid electrolyte interface in a solid-state whole-cell configuration. To investigate the surface of the catalyst layer further, the contact angle of a water droplet was measured for 
all GDE materials (Fig. 5). The high contact angle for both the Pt ALD catalyst on plain carbon and the commercial material showed favorable hydrophobicity for a fuel cell cathode [34]. The more hydrophilic surface of the Pt ALD on functionalized carbon was likely due to the existing functional groups; a resultant phenomenon on acid-like carbon surfaces $[35,36]$. The high contact angle for the plain catalyst further supports maintaining water-managing favorable characteristics of the XC72R by an ALD technique. Whereas, the commercial catalyst methodology likely resulted in slightly compromising the surface, therefore depressing the contact angle. Bulk water behavior on the GDE correlated to water management within the whole-cell wet condition. The functional groups on the XC72R surface of functionalized catalyst impeded water flow within the cell because of the more hydrophilic surface. The functionalized catalyst had better performance in the whole-cell under a lower humidity and higher gas flowrate condition because the catalyst was less compromised by water. A hydrophilic effect was not present for the commercial catalyst, as shown by an overall lower performance within the drier condition. Although not observed to be detrimental in a half-cell, a more hydrophilic carbon surface prevents PEMFC operation. Furthermore, a hydrophilic surface may artificially benefit evaluation in a half-cell since functionality relies on the interface between the electrode and a liquid electrolyte. Therefore, the more hydrophilic functionalized catalyst can only be truly evaluated in a whole-cell.

Efficacy of whole-cell evaluation and revelation of surface-compromised catalysts can be further exploited when considering alternative cell reactions. The catalysts inspected in this investigation were also utilized in a previous report focused on hydrogen pumping [37], with the same MEA composition. We found the ALD catalyst on the functionalized carbon to be superior to the commercial catalyst for hydrogen pumping on the anode. Hydrogen pumping operates on similar phase boundaries to conduct ions, electrons and gases to and away from the reaction site on the anode, but is less prone to flooding. With the same catalyst layer and MEA construction, the catalyst produced on the functionalized carbon was less effective for the ORR on the cathode in this report. Fuel cell cathodes are more sensitive to catalyst layer morphology because of water production, which was influenced by the functionalization 
process producing a lower surface area carbon [37]. Combined with a more hydrophilic interface, the catalyst layer constructed using the functionalized carbon is less fit for the PEMFC cathode. Surface effects were more apparent in the whole-cell fuel cell due to suppression of mass transport limitations in an RDE half-cell. The measured hydrophilicity of the carbon functional groups and the decreased surface area compromised the movement of water away from the cathode catalyst. Because of less effective water management, the catalyst layer was rendered ineffective despite comparable activity to the commercial catalyst within a half-cell's liquid electrolyte, and better performance in lower relative humidity and in a hydrogen pump. Guha et al. compared functionalized carbons via half- and whole-cell evaluation, concluding carbon type had little influence on the catalytic activity in an RDE test, however differences arose within MEAs containing high surface area carbon [38]. In this study, the carbon functional groups degraded performance at the whole-cell level by modifying the catalyst layer morphology and hydrophilicity, despite producing promising Pt nanoparticles. Concurrently, Pt ALD on plain carbon had comparable performance to the commercial catalyst in half-cell evaluation, and higher in whole-cell, illustrating the aptitude of ALD for PEMFC catalyst manufacture.

Contrasting wetter and drier conditions within the whole-cell evaluation exposes considerable water management limitations for the functionalized catalyst. Drier conditions minimized flooding resulting from the hydrophilic groups generated on the surface of the carbon during the functionalization process. Although functionalization assists production of small well-dispersed Pt nanoparticles during the ALD process, the side effect of residual groups on the $\mathrm{XC72R}$ surface detracts from its deposition benefits. Whole-cell evaluation methodology including a battery of tests with drier and wetter conditions can assist exposing the effect of the carbon surface condition on the cell performance, and is recommended for evaluation of PEMFC catalysts.

\subsection{Conclusions}

$\mathrm{Pt} / \mathrm{C}$ catalysts were manufactured for PEMFCs using a hydrogen ALD chemistry in a fluidized bed. Deposition on functionalized carbon produced smaller more dispersed particles, but hydrophilic 
surface groups remained after deposition. ALD-prepared Pt catalysts on plain and functionalized carbon showed comparable or better performance to a commercial catalyst in half-cell tests. Because RDEs minimize transport limitations in a half-cell, the $\mathrm{Pt} / \mathrm{C}$ materials were further evaluated in a whole-cell to increase the sensitivity to interfacial effects. The more hydrophilic functionalized carbon support and modified structure caused flooding at moderate current densities in whole-cell tests, ultimately underutilizing the deposited Pt particles. The hydrophilic surface of the functionalized carbon catalyst showed improved performance within a drier environment, leveraging conditions more favorable for water management to reveal how the carbon surface influences a whole-cell evaluation. However, Pt ALD on a plain carbon produced a catalyst with superior performance and effective water management in a whole-cell under more standard conditions.

Functionalizing carbon supports is a common technique for facilitating precursor attachment during ALD, often resulting in a higher deposition rate and particle dispersion. Although platinum ALD in a fluidized bed is ripe for PEMFC catalyst manufacture, functionalizing a carbon support can produce a hydrophilic catalyst layer that degrades whole-cell performance. This study stimulates further investigation into effective removal techniques, or refinement of the ALD process to eliminate prerequisite surface functional groups that compromise phase boundaries. Because PEMFCs rely on multifunctional material interfaces, whole-cell evaluations are needed to reveal compromising components like flooding and hydrophilic carbon, thereby assisting in necessary system optimization.

\subsection{Acknowledgements}

This material is based upon work supported by the National Science Foundation Graduate Research Fellowship [grant number 1144083]. The authors thank Fred Luizer at University of Colorado Boulder Laboratory of Environmental and Geological Studies (LEGS) for conducting ICP-OES analysis, and at the University of Colorado Boulder Department of Chemical and Biological Engineering, Troy Gould for conducting TEM analysis, Carolyn Schoenbaum for assistance in conducting DRIFTS analysis, Caitlin 
Majlinger, Chip Fisher, and Boris Chubukov and Sarah Bull for chemisorption and LECO analysis, respectively, and Casey Lamarche for her assistance with contact angle image capture and data collection.

\subsection{References}

[1] W.R. Grove, LXXII. On a gaseous voltaic battery, The London, Edinburgh and Dublin Philosophical Magazine and Journal of Science, 21 (1842) 2F.

[2] J. Larminie, A. Dicks, M.S. McDonald, Fuel cell systems explained, Wiley New York2003.

[3] L. Carrette, K.A. Friedrich, U. Stimming, Fuel Cells - Fundamentals and Applications, Fuel Cells, 1 (2001) 5-39.

[4] J.O.M. Bockris, A.J. Appleby, 3. Alkaline fuel cells (AFCs), Energy, 11 (1986) 95-135.

[5] K.T. Chau, Y.S. Wong, C.C. Chan, An overview of energy sources for electric vehicles, Energy Conversion and Management, 40 (1999) 1021-1039.

[6] B.o. Energy, E.S.N.R. Council, D.o. Engineering, P.S.N.R. Council, W.N.A.o. Engineering, The hydrogen economy: Opportunities, costs, barriers, and R\&D needs, National Academies Press2004.

[7] J. Li, X. Liang, D.M. King, Y.-B. Jiang, A.W. Weimer, Highly dispersed Pt nanoparticle catalyst prepared by atomic layer deposition, Applied Catalysis B: Environmental, 97 (2010) 220-226.

[8] S.M. George, Atomic Layer Deposition: An Overview, Chemical Reviews, 110 (2010) 111-131.

[9] B.J. O’Neill, D.H.K. Jackson, J. Lee, C. Canlas, P.C. Stair, C.L. Marshall, J.W. Elam, T.F. Kuech, J.A. Dumesic, G.W. Huber, Catalyst Design with Atomic Layer Deposition, ACS Catal., 5 (2015) 18041825.

[10] J.W. Elam, N.P. Dasgupta, F.B. Prinz, ALD for clean energy conversion, utilization, and storage, MRS Bulletin, 36 (2011) 899-906.

[11] T.D. Gould, A.M. Lubers, B.T. Neltner, J.V. Carrier, A.W. Weimer, J.L. Falconer, J. Will Medlin, Synthesis of supported Ni catalysts by atomic layer deposition, Journal of Catalysis, 303 (2013) 9-15.

[12] L.F. Hakim, J. Blackson, S.M. George, A.W. Weimer, Nanocoating Individual Silica Nanoparticles by Atomic Layer Deposition in a Fluidized Bed Reactor, Chemical Vapor Deposition, 11 (2005) 420-425.

[13] D.M. King, X. Liang, Y. Zhou, C.S. Carney, L.F. Hakim, P. Li, A.W. Weimer, Atomic layer deposition of TiO2 films on particles in a fluidized bed reactor, Powder Technol., 183 (2008) 356-363.

[14] X. Liang, Y. Zhou, J. Li, A. Weimer, Reaction mechanism studies for platinum nanoparticle growth by atomic layer deposition, Journal of Nanoparticle Research, 13 (2011) 3781-3788.

[15] C. Liu, C.C. Wang, C.C. Kei, Y.C. Hsueh, T.P. Perng, Atomic Layer Deposition of Platinum Nanoparticles on Carbon Nanotubes for Application in Proton-Exchange Membrane Fuel Cells, Small, 5 (2009) 1535-1538.

[16] G.-D. Zhan, X. Du, D.M. King, L.F. Hakim, X. Liang, J.A. McCormick, A.W. Weimer, Atomic Layer Deposition on Bulk Quantities of Surfactant-Modified Single-Walled Carbon Nanotubes, Journal of the American Ceramic Society, 91 (2008) 831-835.

[17] Y.-C. Hsueh, C.-C. Wang, C.-C. Kei, Y.-H. Lin, C. Liu, T.-P. Perng, Fabrication of catalyst by atomic layer deposition for high specific power density proton exchange membrane fuel cells, Journal of Catalysis, 294 (2012) 63-68.

[18] A. Lubers, C. Muhich, K. Anderson, A. Weimer, Mechanistic studies for depositing highly dispersed Pt nanoparticles on carbon by use of trimethyl(methylcyclopentadienyl)platinum(IV) reactions with O2 and H2, Journal of Nanoparticle Research, 17 (2015) 1-16.

[19] J. Huang, J. Zhang, M. Eikerling, Theory of electrostatic phenomena in water-filled Pt nanopores, Faraday Discussions, (2016).

[20] P. Staiti, Z. Poltarzewski, V. Alderucci, G. Maggio, N. Giordano, A. Fasulo, Influence of electrodic properties on water management in a solid polymer electrolyte fuel cell, Journal of Applied Electrochemistry, 22 (1992) 663-667. 
[21] Z. Qi, A. Kaufman, Improvement of water management by a microporous sublayer for PEM fuel cells, J. Power Sources, 109 (2002) 38-46.

[22] P. Gode, F. Jaouen, G. Lindbergh, A. Lundblad, G. Sundholm, Influence of the composition on the structure and electrochemical characteristics of the PEFC cathode, Electrochimica Acta, 48 (2003) 41754187.

[23] Y. Garsany, J. Ge, J. St-Pierre, R. Rocheleau, K.E. Swider-Lyons, Analytical Procedure for Accurate Comparison of Rotating Disk Electrode Results for the Oxygen Reduction Activity of Pt/C, J. Electrochem. Soc., 161 (2014) F628-F640.

[24] A.E. Aksoylu, M. Madalena, A. Freitas, M.F.R. Pereira, J.L. Figueiredo, The effects of different activated carbon supports and support modifications on the properties of Pt/AC catalysts, Carbon, 39 (2001) 175-185.

[25] C. Prado-Burguete, A. Linares-Solano, F. Rodríguez-Reinoso, C.S.-M. de Lecea, The effect of oxygen surface groups of the support on platinum dispersion in Pt/carbon catalysts, Journal of Catalysis, 115 (1989) 98-106.

[26] R.V. Hull, L. Li, Y. Xing, C.C. Chusuei, Pt Nanoparticle Binding on Functionalized Multiwalled Carbon Nanotubes, Chemistry of Materials, 18 (2006) 1780-1788.

[27] J.L. Figueiredo, M.F.R. Pereira, M.M.A. Freitas, J.J.M. Órfão, Modification of the surface chemistry of activated carbons, Carbon, 37 (1999) 1379-1389.

[28] G. Socrates, Infrared and Raman characteristic group frequencies: tables and charts, John Wiley \& Sons2004.

[29] K. Kinoshita, Particle Size Effects for Oxygen Reduction on Highly Dispersed Platinum in Acid Electrolytes, J. Electrochem. Soc., 137 (1990) 845-848.

[30] A.J. Martin, A.M. Chaparro, B. Gallardo, M.A. Folgado, L. Daza, Characterization and single cell testing of Pt/C electrodes prepared by electrodeposition, J. Power Sources, 192 (2009) 14-20.

[31] Q. Yan, H. Toghiani, H. Causey, Steady state and dynamic performance of proton exchange membrane fuel cells (PEMFCs) under various operating conditions and load changes, J. Power Sources, 161 (2006) 492-502.

[32] M.G. Santarelli, M.F. Torchio, Experimental analysis of the effects of the operating variables on the performance of a single PEMFC, Energy Conversion and Management, 48 (2007) 40-51.

[33] W.-M. Yan, C.-H. Yang, C.-Y. Soong, F. Chen, S.-C. Mei, Experimental studies on optimal operating conditions for different flow field designs of PEM fuel cells, J. Power Sources, 160 (2006) 284292.

[34] J.H. Nam, M. Kaviany, Effective diffusivity and water-saturation distribution in single- and twolayer PEMFC diffusion medium, International Journal of Heat and Mass Transfer, 46 (2003) 4595-4611.

[35] S.S. Barton, M.J.B. Evans, E. Halliop, J.A.F. MacDonald, Acidic and basic sites on the surface of porous carbon, Carbon, 35 (1997) 1361-1366.

[36] S. Biniak, G. Szymanski, J. Siedlewski, A. Swiatkowski, The characterization of activated carbons with oxygen and nitrogen surface groups, Carbon, 35 (1997) 1799-1810.

[37] A. Lubers, A. Drake, D. Ludlow, A. Weimer, Electrochemical hydrogen pumping using a platinum catalyst made in a fluidized bed via atomic layer deposition, Powder Technol., 296 (2016) 72-78.

[38] A. Guha, T.A. Zawodzinski Jr, D.A. Schiraldi, Evaluation of electrochemical performance for surface-modified carbons as catalyst support in polymer electrolyte membrane (PEM) fuel cells, J. Power Sources, 172 (2007) 530-541.

\section{Figures}




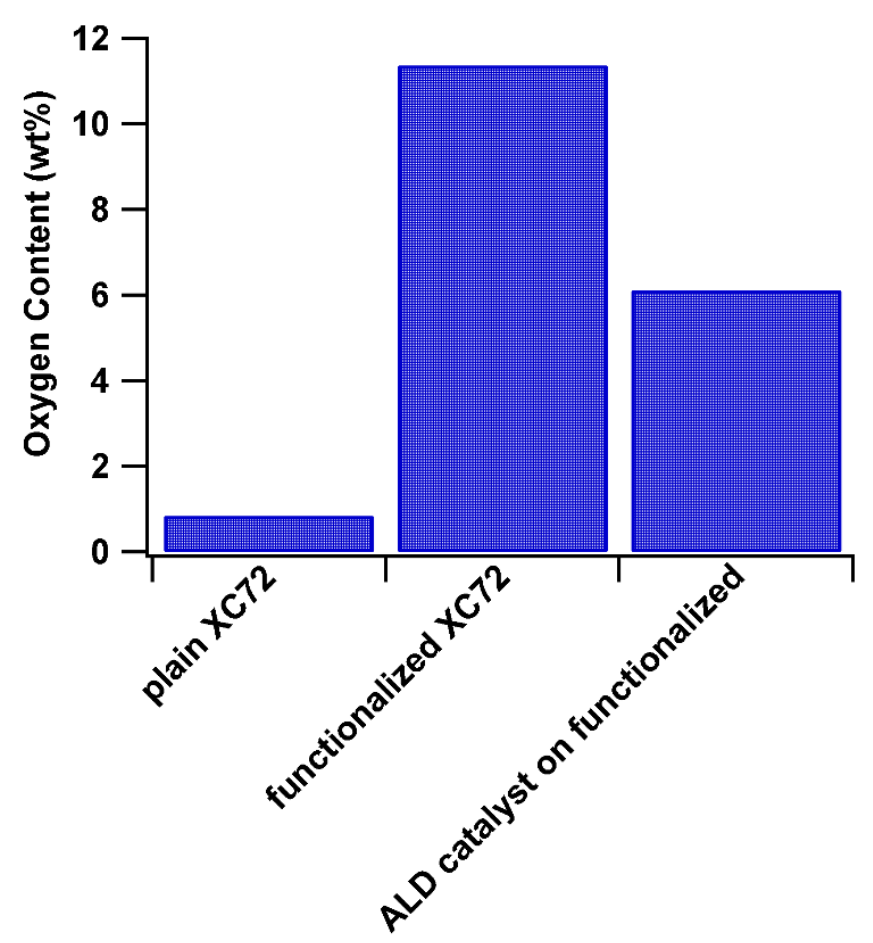

Fig. 1. Total oxygen content of XC72R before platinum deposition, functionalized XC72R before platinum deposition, and functionalized XC72R after platinum deposition via ALD. 

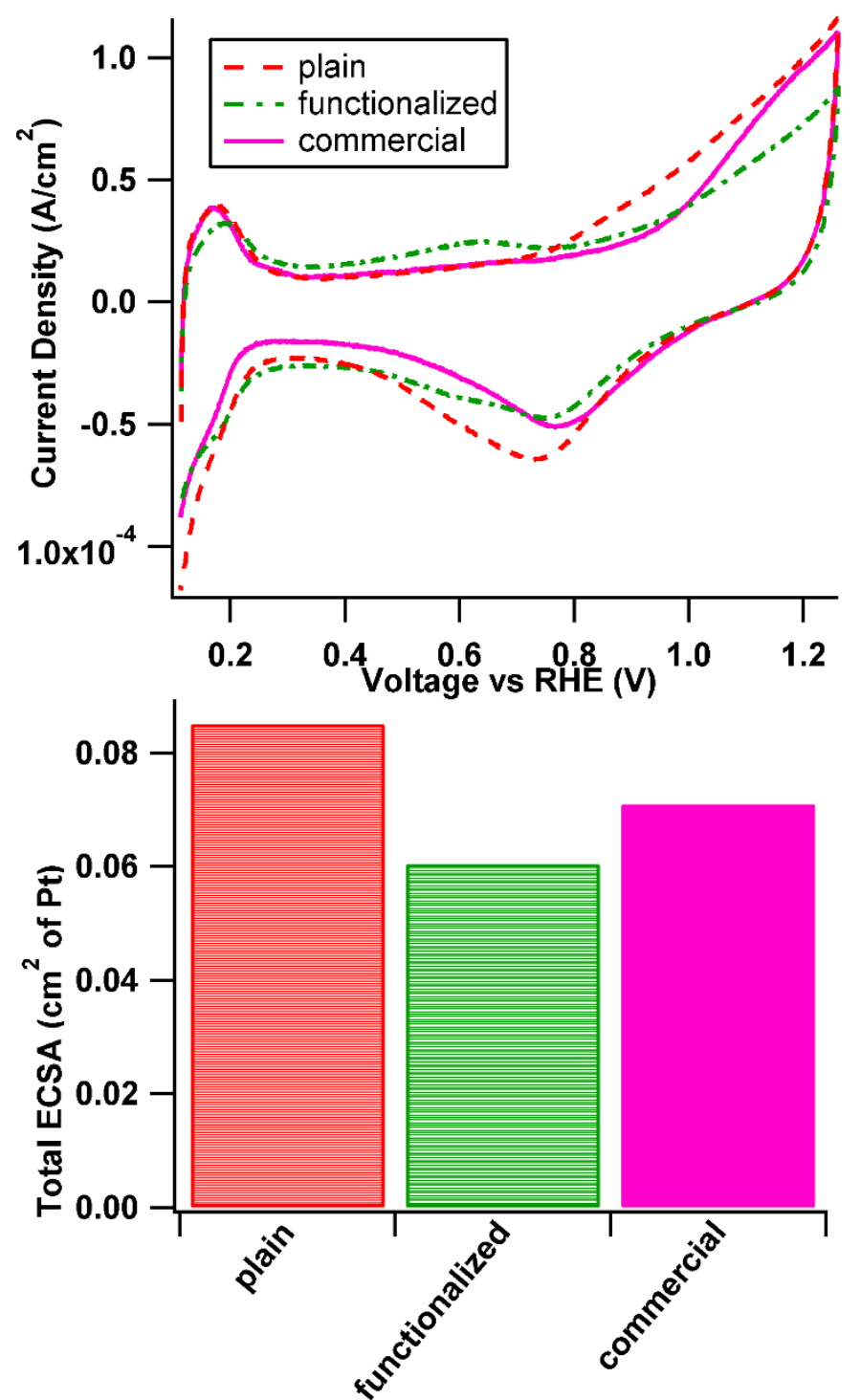

Fig. 2. Half-cell polarization curves in $\mathrm{HClO}_{4}$ for all $\mathrm{Pt} / \mathrm{C}$ materials, voltage vs RHE, cyclic voltammogram and calculated ECSA. 


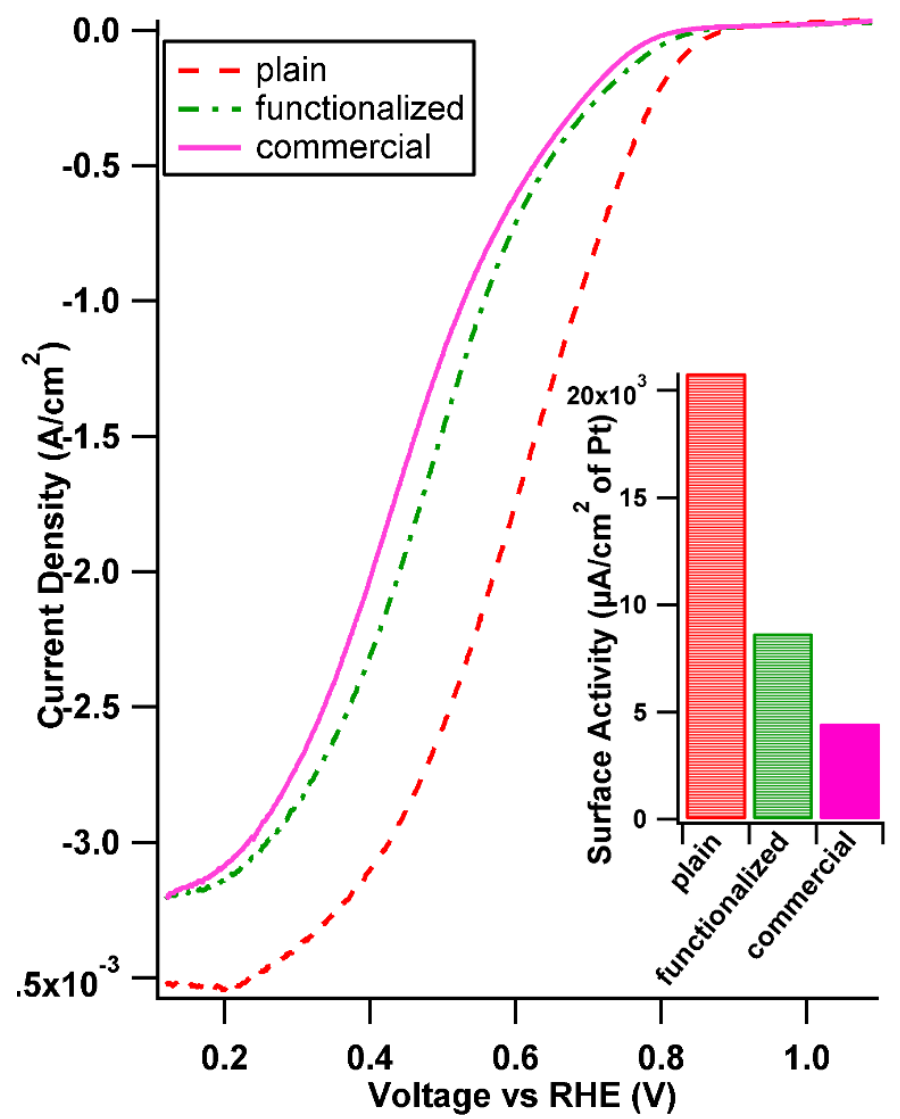

Fig. 3. Half-cell polarization curves in $\mathrm{HClO}_{4}$ for all $\mathrm{Pt} / \mathrm{C}$ materials, voltage vs RHE, and resultant currents at the half-wave potential found at $0.503 \mathrm{~V}$ vs RHE for each catalyst normalized by their measured ECSA.

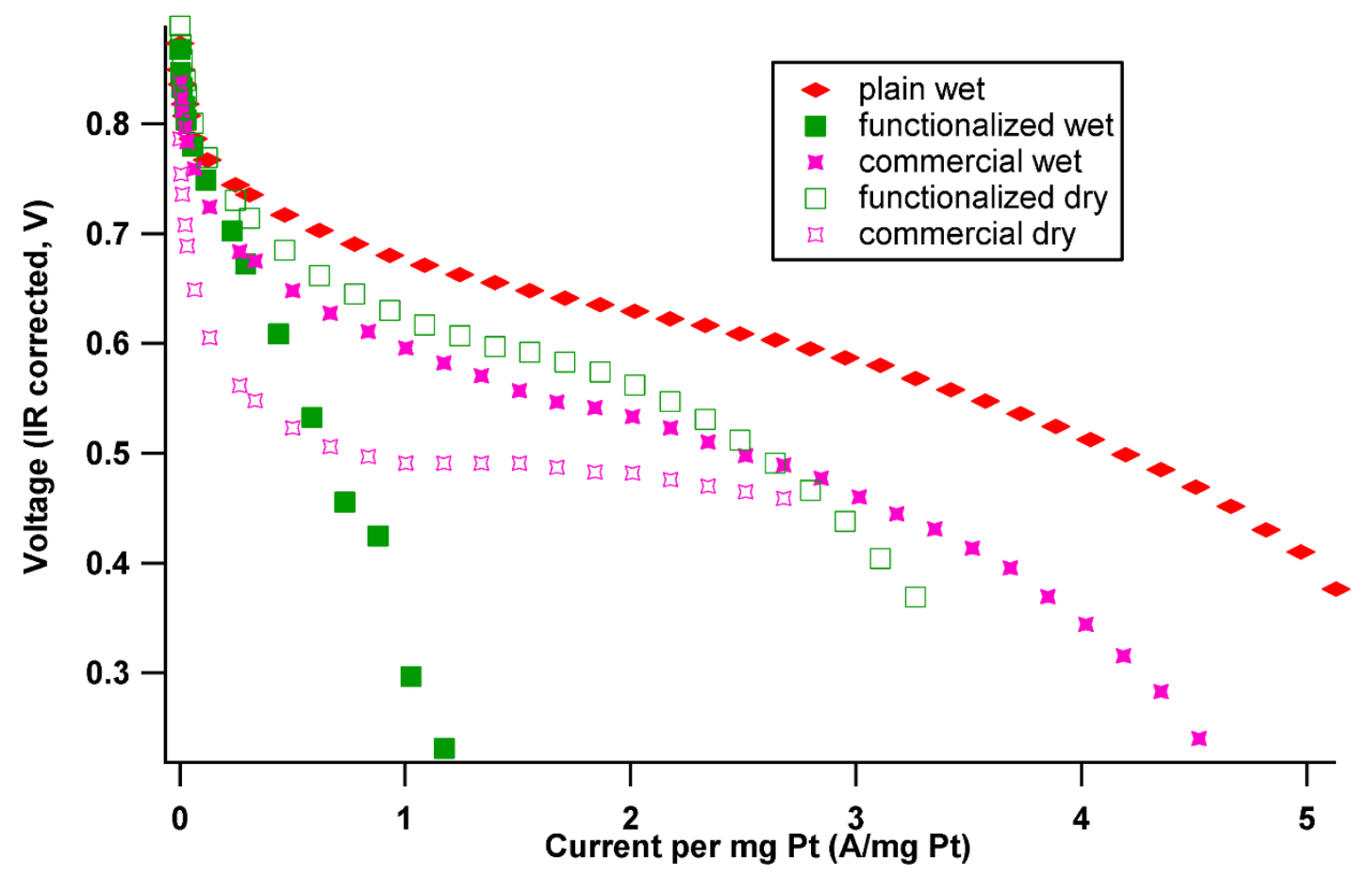


Fig. 4. ALD and commercial catalyst performance in a PEMFC using pure hydrogen on the anode and pure oxygen on the cathode. Wet conditions were at $78 \%$ humidity and a lower gas flowrate (solid markers). Dry test conditions were at $61 \%$ humidity and a higher gas flowrate (hallow markers).

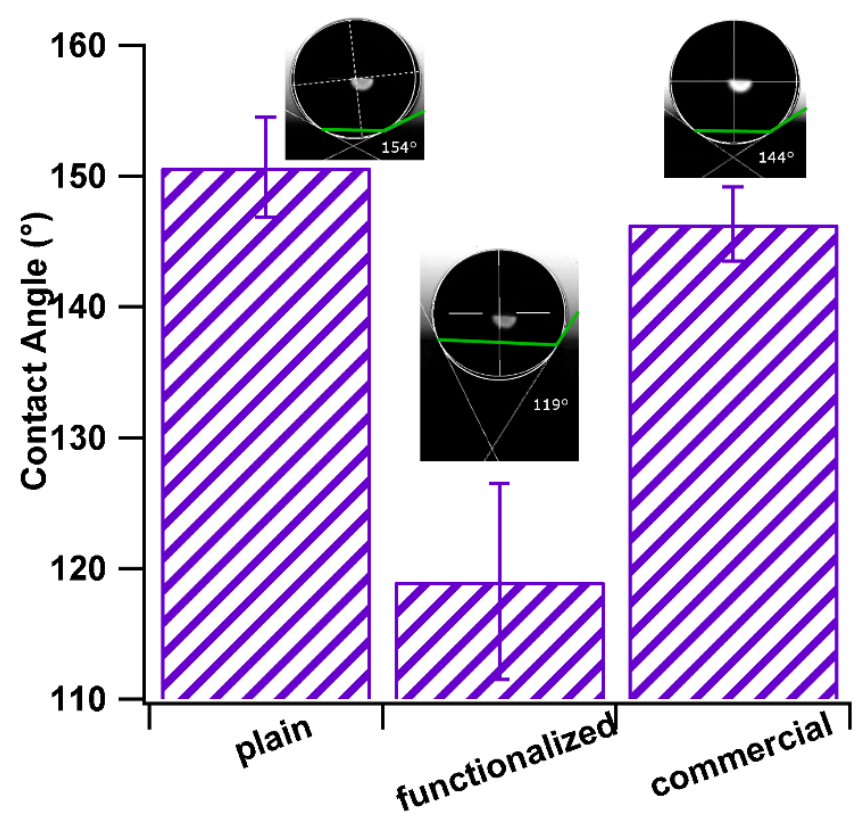

Fig. 5. Contact angle measurements relating to the surface hydrophobicity of the ALD and commercial catalysts, with representative angle measurements for each catalyst type. 